
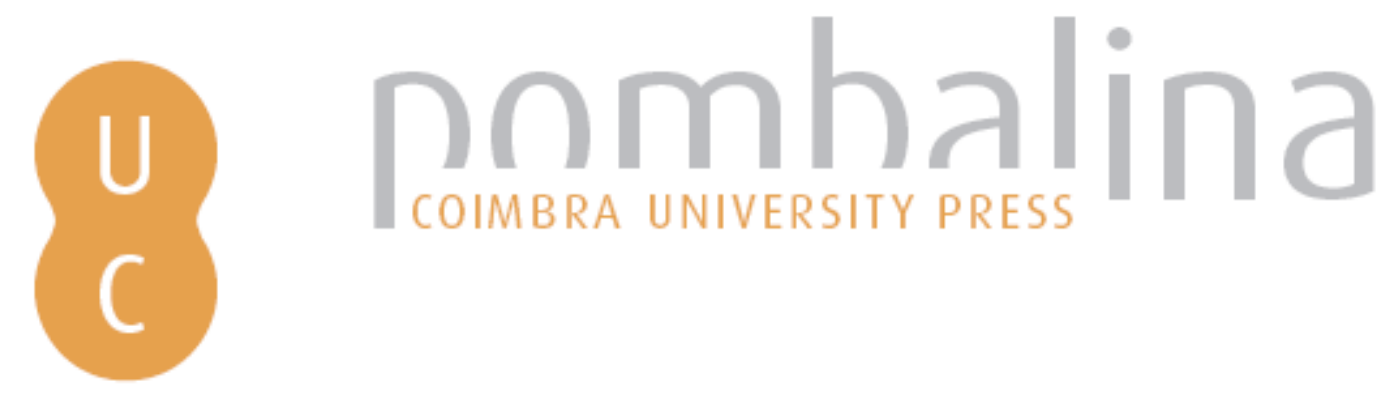

\title{
"A velha e a nova: um novo espaço": o órgão de gestão dos estabelecimentos de ensino público e o centro novas oportunidades
}
Autor(es):
Gama, Manuel; Vieira, Diana Aguiar; Coimbra, Joaquim Luís
Publicado por: Imprensa da Universidade de Coimbra
URL
persistente:
URI:http://hdl.handle.net/10316.2/31243
DOI:
DOI:http://dx.doi.org/10.14195/978-989-26-0228-8_9
Accessed : $\quad$ 26-Apr-2023 12:50:43

A navegação consulta e descarregamento dos títulos inseridos nas Bibliotecas Digitais UC Digitalis, UC Pombalina e UC Impactum, pressupõem a aceitação plena e sem reservas dos Termos e Condições de Uso destas Bibliotecas Digitais, disponíveis em https://digitalis.uc.pt/pt-pt/termos.

Conforme exposto nos referidos Termos e Condições de Uso, o descarregamento de títulos de acesso restrito requer uma licença válida de autorização devendo o utilizador aceder ao(s) documento(s) a partir de um endereço de IP da instituição detentora da supramencionada licença.

Ao utilizador é apenas permitido o descarregamento para uso pessoal, pelo que o emprego do(s) título(s) descarregado(s) para outro fim, designadamente comercial, carece de autorização do respetivo autor ou editor da obra.

Na medida em que todas as obras da UC Digitalis se encontram protegidas pelo Código do Direito de Autor e Direitos Conexos e demais legislação aplicável, toda a cópia, parcial ou total, deste documento, nos casos em que é legalmente admitida, deverá conter ou fazer-se acompanhar por este aviso.

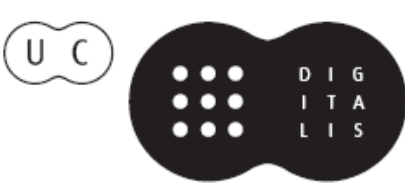




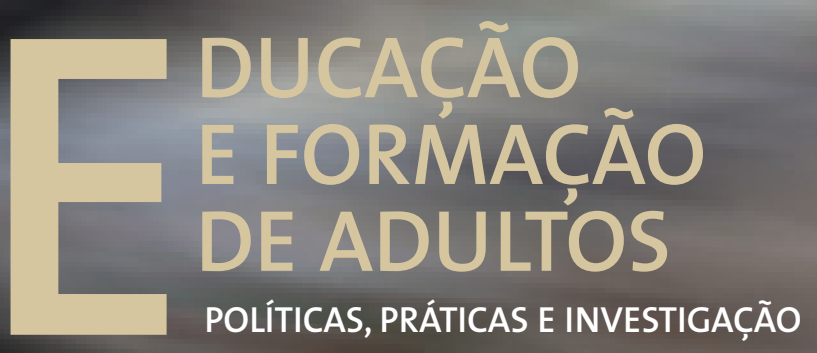

Luís Alcoforado • Joaquim Armando G. Ferreira António Gomes Ferreira • Margarida Pedroso de Lima Cristina Vieira • Albertina L. Oliveira • Sónia Mairos Ferreira 


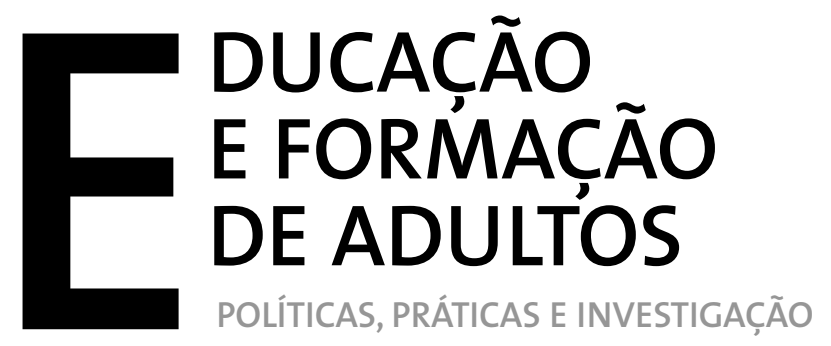

Luís Alcoforado • Joaquim Armando G. Ferreira António Gomes Ferreira - Margarida Pedroso de Lima Cristina Vieira • Albertina L. Oliveira • Sónia Mairos Ferreira 
EDIÇÃo

Imprensa da Universidade de Coimbra

URL: http://www.uc.pt/imprensa_uc

Vendas online: http://www.livrariadaimprensa.com

CONCEPÇÃO GRÁFICA

António Barros

Pré-Impressáo

SerSilito-Empresa Gráfica, Lda

EXECUÇÃo GRÁFICA

SerSilito-Empresa Gráfica, Lda

ISBN

978-989-26-0136-6

DePósito LEgaL

$340309 / 12$ 



\author{
"A velha e a Nova - Um Novo Espaço" \\ O ÓRGÃo DE GESTÁo dOS ESTABELECIMENTOS DE ENSINO PÚBLICO \\ e o Centro Novas Oportunidades
}

\author{
Manuel Teiga Gama \\ Diana Aguiar Vieira \\ Joaquim Luís Coimbra \\ Universidade do Porto
}

\title{
1. 2000 - Uma intenção, uma trajectória nacional
}

Desde 2000 que a tónica na Aprendizagem ao Longo da Vida (ALV) tem verificado a sua intensificação, nomeadamente na sequência do Conselho Europeu de Lisboa, na qual se definiu a estratégia de incremento de uma sociedade do conhecimento com níveis de competitividade mais elevada e de maior dinamismo face ao crescimento económico, emprego e coesão social. Neste paradigma de ALV inscrevem-se o reconhecimento e a validação de competências num quadro de referência em que os adquiridos se constituem como basilares para os percursos de aprendizagem característicos das sociedades do conhecimento.

A problematização e consequente valoração das aprendizagens formais, não formais e informais que os adultos efectivam no decorrer das suas trajectórias pessoais, e socioprofissionais assumem-se cada vez mais como um campo teórico-conceptual onde reemergem práticas diversas, contudo revestidas de um insuficiente suporte científico. É na prática recente de reconhecimento, validação e certificação de competências que estas orientaçóes têm encontrado os seus alicerces legais. De forma a enquadrar o seu delineamento políticolegal, passamos a apresentar o seu desenvolvimento no contexto português.

A criação da Agência Nacional de Educação e Formação de Adultos (ANEFA ${ }^{1}$ ) verifica a sua criação em 1999, ano em que a Educação e Formação de Adultos se implanta no contexto português. Em 2000, constitui-se o regulamento dos cursos EFA². O consequente caminhar para o campo da certificação de competências originou a definição de um Sistema de Acreditação de Conhecimentos e Competências fora do Sistema Escolar, sistema este recomendado pelo Programa Operacional da Educação (PRODEP). Emerge assim no contexto português, em 2001, a rede nacional de Centros de Reconhecimento, Validação e Certificaçáo de Competências, constituindo-se assim a base de promoção do Sistema Nacional de Reconhecimento, Validação e Certificação de Competências ${ }^{3}$. O Sistema Nacional de RVCC organizou-se tendo por base o referencial de competências chave para a Educação e Formação de Adultos e o regulamento do processo de acreditação das entidades promotoras de centros RVCC. O implante e desenvolvimento desta política educativa direccionada à população adulta portuguesa verifica no período decorrente entre 2001 e 2005 a criação de 98 centros de RVCC. Neste período (2001-2005), acontece a

\footnotetext{
1 1999, Decreto-Lei n. $387 / 99$ de 28 de Setembro - Criaçăo da Agência Nacional para a Qualificação. 2000, Despacho Conjunto n. ${ }^{\circ} 1083 / 00$ de 20 de Novembro.

3 2001, Portaria n. ${ }^{\circ} 1082-\mathrm{A} / 2001$, de 8 de Setembro (revogada pelas portarias n. ${ }^{\circ}$ 286-A/02, de 15 de Março, e n. ${ }^{\circ} 86 / 07$, de 12 de Janeiro.
} 
extinção da ANEFA e sucede-lhe a Direcção-Geral de Formação Vocacional ${ }^{4}$ (DGFV). Estando numa fase de definição das opçôes estratégicas no campo de ducação e formação da população adulta no contexto português, são definidas as Grandes Opçóes do Plano 2005-20095 , com vista à qualificação da população adulta e à sua motivação para a criação de oportunidades no campo da aprendizagem ao longo da vida.

A premente necessidade de desenvolvimento das qualificaçóes da população adulta e o travar o abandono precoce do sistema de ensino português foram as condicionantes que estiveram na aprovação do Plano Tecnológico ${ }^{6}$ (2005) onde são definidos os objectivos da Iniciativa Novas Oportunidades (INO). A INO encontra o seu fundamento no Programa Nacional de Acçáo para o Crescimento e o Emprego 2005-20087 apostando no reforço e expansão do ensino profissionalizante de dupla certificação, cursos EFA e sistema RVCC. A crescente aposta nestas iniciativas levou à criaçáo do Referencial de Competências-Chave para a Educação e Formação de Adultos de Nível Secundário a aplicar nos contextos dos cursos EFA e nos processos de RVCC. A operacionalizaçáo das políticas de educação e formação dá origem à criação da Agência Nacional para a Qualificação ${ }^{8}$ (ANQ) em 2007e o governo aprova a Reforma da Formação Profissional ${ }^{9}$, o Sistema Nacional de Qualificaçóes $^{10}$ (SNQ) que integra o Quadro Nacional de Qualificaçóes, Catálogo Nacional de Qualificaçóes, Caderneta Individual de Competências e Sistema de Regulação de Acesso a Profissóes. A actual conjuntura das políticas de emprego e formação encontra as suas prioridades estratégicas definidas no actual Quadro de Referência Estratégica nacional (QREN - 2007-2013) através do Programa Operacional Potencial Humano (POPH) que procuram combater o deficit estrutural dos níveis de qualificação da população portuguesa, estabelecendo o nível secundário como referencial mínimo de qualificação para a população jovem e adulta.

A temática da ALV, emerge como consequência das sociedades do conhecimento cujas nuances se fazem sentir ao nível das diversas economias e sociedades. É tida como uma medida de educação e formação, levando a produção do Memorando sobre a Aprendizagem ao Longo da Vida, lançando o debate à escala europeia sobre uma estratégia global (Comissão das Comunidades Europeias, 2000 ${ }^{11}$ ).

Este documento defende a ALV assente em "toda a actividade de aprendizagem em qualquer momento da vida, com o objectivo de melhorar os conhecimentos, as aptidóes e competências, no quadro de uma perspectiva pessoal, cívica e social e/ou relacionada com o emprego" (Sitoe, 2006, p.284). O memorando a aprendizagem ao longo da vida (Comissão das Comunidades Europeias, 2000) remete para uma estratégia concertada inerente às actuais e emergentes mudanças nos diversos contextos sociais e económicos focalizada na educação e formação. A ALV é assim sublinhada com carácter prioritário ao

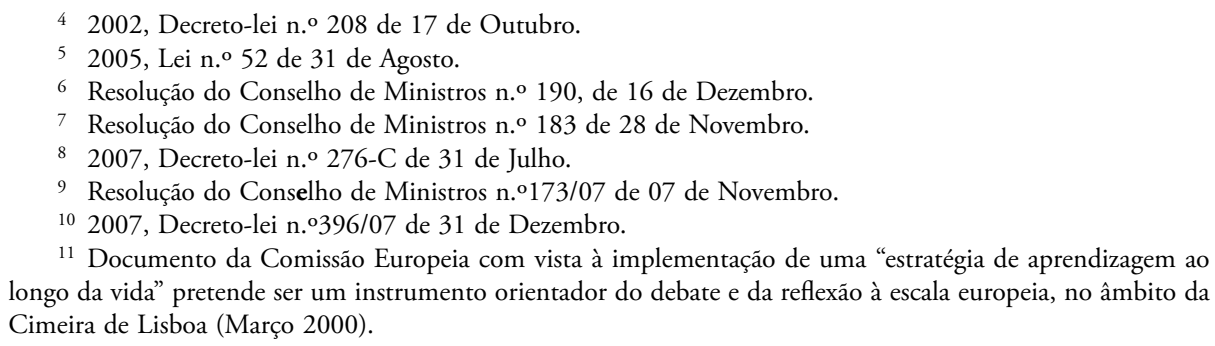

11 Documento da Comissão Europeia com vista à implementação de uma "estratégia de aprendizagem ao longo da vida" pretende ser um instrumento orientador do debate e da reflexáo à escala europeia, no âmbito da Cimeira de Lisboa (Março 2000). 
nível das políticas europeias com vista ao crescimento e coesão social em sociedades ditas do conhecimento.

\section{Educaçáo e formaçáo ao longo da vida - uma trajectória educativa}

A formação e o ensino desde que perspectivados ao longo da vida constituem-se como vectores indispensáveis à promoçáo da adaptabilidade, empregabilidade, ao desenvolvimento pessoal e profissional, tornando o cidadão um participante activo face aos actuais mecanismos globalizantes que tanto caracterizam as actuais sociedades, concretamente as que se mobilizam no contexto europeu. No contexto português a emergência da INO contempla nos seus eixos de intervenção como destinatários os adultos e assume como principal vector a ALV. Perante a implementação da INO em contexto escolar, o fenómeno mudança assume um carácter fulcral. No respeitante ao eixo Adultos a INO toma forma através do desenvolvimento de Processo RVCC e das ofertas formativas de educação e formação de adultos. No actual contexto, as instituições de ensino público assumem-se cada vez mais como agentes locais, onde as opçóes estratégicas globais, comunitárias e nacionais devem tomar corpo.

Neste campo de intervenção da orientação vocacional e profissional, estas políticas educativas encontram o um imperativo num olhar informativo, desenvolvimentista, construtivista e mesmo ecológico, potenciando assim o desenvolvimento de projectos pessoais, sócias e profissionais (Reis, 2008). As conceptualizaçóes das políticas educativas encontram-se envoltas em quadros orientadores numa perspectiva globalizante e de convergência europeia. Ball (2001, p. 100) refere:

"por vezes se denomina "convergência de políticas" ou transferência de políticas (Dolowitz, Hulme, Nellis \& O’Neill, 2000) ou ainda empréstimo de políticas (Halpin \& Troyna, 1955; Whitty \& Edwards, 1998). Dito de outra forma, (...) até que ponto estamos a assistir ao desaparecimento gradual da concepção de políticas específicas do Estado Nação nos campos económico social e educativo e, concomitantemente, o abarcamento de todos estes campos numa concepção única de políticas para a competitividade económica, ou seja, o crescente abandono ou marginalização (não no que se refere à retórica) dos propósitos sociais da educação".

Tuschling e Engemann (2006, citado por Alves, 2010) defendem a tese que a centralidade e posicionamento crescente da temática da educação e formação ao longo da vida nas políticas europeias têm levado à emergência da era da ALV. Neste sentido Lima (2003, citado por Alves, 2010), refere que o protagonismo conceptual e a apologia actualmente registados pelas ideias de formação ao longo da vida e, especialmente, de aprendizagem ao longo da vida, náo têm precedentes na história das políticas educativas e em geral, das políticas sociais.

A emergência de novas práticas educativas surge imersa na sociedade do conhecimento e na ALV. Neste contexto, Pires refere que: 
"considerando as profundas mutaçóes decorrentes da globalização das economias, da evolução do mundo do trabalho e das organizaçóes, da emergência da sociedade do conhecimento e da aprendizagem ao longo da vida, esta problemática adquires uma relevância particular. $\mathrm{O}$ reconhecimento e a validação inscrevem-se (...) num quadro de pensamento que valoriza as aprendizagens que as pessoas realizam ao longo das suas trajectórias pessoais, sociais e profissionais, ultrapassando as tradicionais fronteiras espaço-temporais delimitadas institucionalmente pelos sistemas de educaçáo/formação. Num contexto de atenuação de fronteiras entre educação, formação, trabalho e lazer, o reconhecimento das aprendizagens experienciais - principalmente de adultos - constituise como um desfia incontornável aos sistemas de educação/formação nos dias de hoje". (Pires, 2009, p. 7)

A importância do conhecimento e a sua valorização veio permitir o desenvolvimento de sociedades individualistas, contudo, mais críticas face ao mundo. O foco é na mudança/ transformaçáo social a par da mudança/transformação pessoal, tomando consciência das actuais sociedades e consequente necessidade de intervir. Conforme, Coimbra et al (2001, p. 107):

\begin{abstract}
"Vivemos num período dominado pela ocorrência contínua e acelerada de uma pluralidade de mudanças com reflexos nas mais variadas esferas de funcionamento da vida em sociedade que, para a generalidade dos seus cidadáos, se fazem sentir sob a forma de uma crescente incerteza e ambivalência quanto às direcçóes futuras que as suas existências irão tomar, tanto no plano individual como no social. No centro de todas estas transformaçóes encontram-se os significativos avanços tecnológicos que, nos últimos anos, se vêm sucedendo a um ritmo veloz e simultaneamente gerador de rápidas e profundas alteraçóes nas estruturas e regras de funcionamento dos sistemas económicos. A ênfase no desenvolvimento de organizaçóes de trabalho flexíveis, na estrutura e modo de funcionamento, assentes em recursos humanos (altamente) especializados, mas polivalentes, que lhes permitam um elevado grau de responsividade e de capacidade imediata de reajustamento às exigências de criatividade, adaptabilidade impostas por uma economia de grande competitividade (no plano nacional e internacional), leva a (e ao mesmo tempo exige) um aumento generalizado nós níveis de instrução e de qualificação da população, bem como uma actualização e reconversão continuada das competências e conhecimentos inicialmente adquiridos pelos sujeitos".
\end{abstract}

É neste quadro de necessidades que as políticas de Educação e Formação de Adultos se assumem como as principais linhas no que concerne aos processos de reconhecimento, aquisição e desenvolvimentos de competências, "New Skills", pessoais e profissionais. Le Boterf (1995) refere o conceito de competência (recursos e habilidades) que o indivíduo deverá ser capaz de, num determinado contexto, mobilizar, integrar e transferir, para agregar valor económico à organização e valor social ao indivíduo. É esta abordagem economicista do conhecimento que Gorz (2003) denomina de "economia do conhecimento". Contudo, Gorz defende um indivíduo activo constituindo-se como co-construtivo da sua realidade, autoregulador dos seus processos experienciais, valorizando-se e assumindo-se como especulador de si próprio. São assim os indivíduos os principais actores das sociedades do conhecimento. É a sua capacidade de construção, de desenvolvimento e de utilizaçáo do conhecimento que é valorizada pelas actuais sociedades em constantes e profundas reestruturaçóes. A ALV é 
postulada como um processo gradual, gradativo, cumulativo e perspectivada num contínuo em que se consideram a dimensáo temporal do processo de aprendizagem (lifelong) e, a dimensão contextual do processo de aprendizagem (lifewide), os quais podem ser múltiplos.

Os conceitos de aprendizagem forma, não formal e informal, ecoam na literatura com as seguintes características: aprendizagem formal, verificasse em instituiçóes de ensino e formaçâo e conduz à aquisição de diplomas, certificados; a aprendizagem não-formal é decorrente de acçóes externas aos sistemas formais como sejam os adquiridos no mundo laboral, participação associativa e comunitária entre outras e que podem ou não conduzir à certificação; a aprendizagem informal consiste na aprendizagem consubstanciada em situaçóes de vida com um carácter mais amplo e que não é reconhecida.

No espaço europeu a ALV tem sido objecto de discussão e desenvolvimento político concretizando-se na Estratégia Europeia para o Emprego (EEE) na tentativa de especificação de respostas para o mercado de trabalho. A ALV é uma proposta apresentada pelo Livro Branco, sendo em 1996 designado pelo Conselho dos Ministros e pelo Parlamento Europeu como o "Ano Europeu da Educação e da Formação ao Longo da Vida". No espaço nacional, a aposta nos cursos de Educação e Formação de Adultos (EFA) e Centro Novas Oportunidades (CNO), constituíram-se como fortes indícios de mudança. Canário (2006, p. 12) refere que estas novidades muitas mediatizadas nos últimos anos, não aparecem do nada e foram pensadas "em articulação com outras medidas, como por exemplo os Clubes Saber Mais ou os Organizadores Locais de Educação e Formação." É oportuno salientar que a Educação e Formação de Adultos assume elevados níveis de importância quando equacionada com o desenvolvimento local. Só indivíduos qualificados podem promover os índices de desenvolvimento da competitividade dos mercados onde as empresas actuam. Alberto Melo (2005, p. 110) refere, "sem educação e formação de adultos, quanto a mim, não há um verdadeiro desenvolvimento local, haverá sim um certo número de decisôes de tipo tecnocrático, de tipo burocrático, de tipo economicista”. É primordial potenciar "cidadãos cada vez mais informados, mais conscientes e, porventura, mais activos” (op.cit., p. 107).

No cerne do Plano Tecnológico (PT), as políticas de Educação e Formação de Adultos constituem-se como vectores da aprendizagem ao longo da vida pelo que em Portugal se têm orientado para a criação de oportunidades, prova disso o slogan "novas oportunidades", orientada para públicos que se caracterizam pelo deficit ao nível das suas qualificaçôes. É no contexto do conhecimento, da decisão política e da acção pública em educação que podemos equacionar o desenvolvimento económico, cultural e social sustentável das actuais sociedades globalizantes e ditas sociedades do conhecimento. Assente neste postulado, a INO propóe-se elevar os níveis de qualificação da população adulta portuguesa definindo o nível secundário ( $12^{\circ}$ ano de escolaridade) como referência. Interessa salientar que é neste domínio social dos adultos pouco escolarizados que se encontra muitas vezes o risco de exclusão social (Melo, 2007).

\section{Estudo empirico}

\subsection{Objectivos}

Para a obtenção de elementos que contribuam para a presente reflexão subjacente à realidade social do funcionamento e integraçáo dos Centros Novas Oportunidades em 
contexto escolar do sistema de ensino público português procurou-se perceber: 1) Qual o significado que o órgáo de gestão de um estabelecimento de ensino público do sistema de ensino português com Centro Novas Oportunidades implementado detém sobre a decisão / implementação do Centro Novas Oportunidades; 2) Integração do Centro Novas Oportunidades na dinâmica da escola; 3) Articulação do Centro Novas Oportunidades com o exterior; 4) Relação entre Centro Novas Oportunidades e qualidade e 5) Centro Novas Oportunidades e definição vs Redefinição de projectos pessoais e profissionais.

\subsection{Metodologia}

Consubstanciada na realidade a investigar, o plano metodológico segue um paradigma qualitativo que, no quadro de uma visão fenomenológica, procura compreender o ponto de vista do órgão de gestão (Director), dos estabelecimentos de ensino público face ao Centro Novas Oportunidades. É um estudo fundamentado pela realidade, orientado para a descoberta, exploratório, descritivo e indutivo.

\subsubsection{Participantes}

Os participantes desta investigação foram cinco directores de estabelecimentos de ensino público com Centro Novas Oportunidades implementado, localizados na regiáo do Vale do Sousa, nomeadamente, nos concelhos de Paredes, Penafiel, Lousada, Felgueiras e Paços de Ferreira.

\subsubsection{Instrumentos}

Para a presente investigação foi construído um guião de entrevista, obedecendo a uma estrutura semi-estruturada. $\mathrm{O}$ guião de entrevista encontra-se estruturado em conjuntos de questóes organizadas em funçáo dos objectivos pretendidos, conforme (Tabela 1).

Tabela 1. Estrutura Guião de Entrevista

\begin{tabular}{ll}
\hline \multicolumn{1}{c}{ Objectivo de Investigaçáo } & \multicolumn{1}{c}{ Questáo de Entrevista } \\
\hline Decisão de implementação do CNO. & $\begin{array}{l}\text { De quem foi a decisão de implementação do centro? } \\
\text { O que motivou a decisão? }\end{array}$ \\
\hline Integração do CNO na dinâmica escolar. & $\begin{array}{l}\text { Qual o significado do CNO integrado no contexto escolar? } \\
\text { Com a introdução do CNO no contexto escolar o que mudou? }\end{array}$ \\
\hline Articulação do CNO com o exterior. & $\begin{array}{l}\text { Como vê a articulação do CNO com o exterior? } \\
\text { Como avalia o estabelecimento de protocolos? } \\
\text { Qual o papel do CNO face à comunidade? }\end{array}$ \\
\hline Relaçáo do CNO com a qualidade. & $\begin{array}{l}\text { Qualidade e metas. O que pensa acerca desta questão? } \\
\text { Em termos nacionais como avalia as metas propostas? }\end{array}$ \\
\hline $\begin{array}{l}\text { Relação CNO e definição vs. Redefinição } \\
\text { de projectos pessoais e profissionais }\end{array}$ & $\begin{array}{l}\text { Qual o impacto do trabalho desenvolvido pelo seu CNO na } \\
\text { vida dos adultos? } \\
\text { Após término do processo de certificação, como sente os adultos } \\
\text { numa perspectiva pessoal? E em termos profissionais? }\end{array}$ \\
\hline
\end{tabular}


No sentido de uma melhor compreensão dos significados do órgão de gestão sobre o Centro Novas Oportunidades a entrevista assumiu uma direcção semi-estruturada de forma a criar condiçóes para aprofundamento do campo reflexivo sobre a temática.

\subsubsection{Procedimentos}

O período de recolha de dados desta investigação decorreu entre Dezembro de 2010 e Fevereiro de 2011. Num primeiro momento, foi agilizado um contacto com os Directores dos estabelecimentos de ensino dos diversos concelhos em estudo com a finalidade de solicitação da autorização de recolha de dados. Num segundo momento procedeu-se à concretização do consentimento informado, tendo sido explanados os objectivos da investigação, a pertinência da investigação e a garantia da confidencialidade e anonimato dos dados. Num terceiro momento procedeu-se à realização das entrevistas, as quais foram gravadas em áudio. Por último, procedeu-se à transcrição integral das entrevistas. $\mathrm{O}$ tratamento das respostas dos Directores às entrevistas assentou na análise de conteúdo, de onde derivam a sua codificação e categorização.

\section{Apresentação e discussáo de resultados}

Os resultados que passamos a apresentar sáo, naturalmente, preliminares em virtude de o estudo se encontrar em fase de desenvolvimento. Para facilitar a análise e discussão dos resultados, à sua apresentaçáo segue a estrutura dos objectivos predefinidos para o estudo.

Tabela 2. Percepção da Decisão de Implementação do Centro Novas Oportunidades

\begin{tabular}{|c|c|c|}
\hline Categoria & Subcategoria & Exemplo de citação \\
\hline Determinaçáo da Tutela & & $\begin{array}{l}\text { “...a determinação do projecto CNO foi determinado } \\
\text { pela tutela, cabe-nos dar corpo ao projecto (...) mas } \\
\text { foi por determinação superior..." }\end{array}$ \\
\hline \multirow{2}{*}{ Ensino Recorrente } & $\begin{array}{l}\text { Com Tradição Ensino } \\
\text { Recorrente }\end{array}$ & $\begin{array}{l}\text { “...como já trabalhávamos com o ensino recorrente } \\
\text { nocturno, sempre vimos esta iniciativa como algo que } \\
\text { daria continuidade..." }\end{array}$ \\
\hline & $\begin{array}{l}\text { Sem Tradição Ensino } \\
\text { Recorrente }\end{array}$ & $\begin{array}{l}\text { “...nunca tínhamos trabalhado com o ensino recor- } \\
\text { rente nocturno e no inicio não estávamos familiari- } \\
\text { zados, mas a nossa escola foi identificada..." }\end{array}$ \\
\hline \multirow[t]{2}{*}{ Comunidade Local } & $\begin{array}{l}\text { Mecanismo de desenvol- } \\
\text { vimento cultural e social }\end{array}$ & $\begin{array}{l}\text { “...a escola hoje é vista como uma forma de chegar } \\
\text { à comunidade }(\ldots) \text { permite um desenvolvimento de } \\
\text { iniciativas culturais e sociais..." }\end{array}$ \\
\hline & $\begin{array}{l}\text { Mecanismo } \\
\text { Inter-geracional }\end{array}$ & $\begin{array}{l}\text { "...é muito engraçado, hoje assistimos a uma realidade } \\
\text { em que temos pais e filhos na escola..." }\end{array}$ \\
\hline
\end{tabular}

Inerente ao parâmetro em análise na Tabela 2, o órgão de gestão (Director), percepciona a decisão como uma imposição da tutela e uma obrigatoriedade ao nível da implementação e desenvolvimento do projecto Centro Novas Oportunidades. Verifica-se a percepção de falta de envolvimento na tomada de decisão de implementação. 
Tabela 3. Percepção da Integração do Centro Novas Oportunidades na Dinâmica Escolar

\begin{tabular}{|c|c|c|}
\hline Categoria & Subcategoria & Exemplo de citaçáo \\
\hline Significado - Resposta & & $\begin{array}{l}\text { “...dar resposta às necessidades de educação e formaçáo } \\
\text { da população adulta e jovem adulta” }\end{array}$ \\
\hline Integração obrigatória & & $\begin{array}{l}\text { "... resposta que as escolas publicas são obrigadas a } \\
\text { dar face à necessidade da populaçáo..." }\end{array}$ \\
\hline Qualidade & & “...temos que dar qualidade a essas respostas...” \\
\hline $\begin{array}{l}\text { Aprendizagem ao longo } \\
\text { da vida }\end{array}$ & $\begin{array}{l}\text { Agentes Educativos } \\
\text { População em geral }\end{array}$ & $\begin{array}{l}\text { “... veio fazer com que a formaçáo e a aprendizagem } \\
\text { ao longo da vida quer para os agente educativos quer } \\
\text { para a população em geral...”." }\end{array}$ \\
\hline \multirow[b]{2}{*}{ Significado - Resultados } & $\begin{array}{l}\text { Profissionais afectos ao } \\
\text { CNO }\end{array}$ & $\begin{array}{l}\text { “...resposta positiva às necessidades formativas..."; } \\
\text { "...trabalho de dignificação para os profissionais e } \\
\text { de valorização para os adultos..." }\end{array}$ \\
\hline & $\begin{array}{l}\text { Profissionais nấo afectos } \\
\text { ao CNO }\end{array}$ & $\begin{array}{l}\text { “...trabalho estatístico fundamentado na opinião } \\
\text { pública e comunicação social...”; “....obtenção de } \\
\text { certificados de forma fácil sem proveito para as pessoas } \\
\text { em particular e a sociedade em geral...” }\end{array}$ \\
\hline \multirow{2}{*}{ Integração } & $\begin{array}{l}\text { Com Tradição Ensino } \\
\text { Recorrente }\end{array}$ & $\begin{array}{l}\text { "...foi um processo natural }(\ldots) \text { a escola à noite } \\
\text { apenas mudou de nome" }\end{array}$ \\
\hline & $\begin{array}{l}\text { Sem Tradiçáo Ensino } \\
\text { Recorrente }\end{array}$ & $\begin{array}{l}\text { "...houve necessidade de nos adaptarmos de nos } \\
\text { ajustarmos..." }\end{array}$ \\
\hline $\begin{array}{l}\text { Diferenciação face ao } \\
\text { modelo anterior }\end{array}$ & & $\begin{array}{l}\text { “...ponto de partida diferenciado face ao ensino } \\
\text { recorrente nocturno, em que a fase inicial assume } \\
\text { grande importância..." }\end{array}$ \\
\hline
\end{tabular}

Quanto à integração do Centro Novas Oportunidades (Tabela 3), a integração destas estruturas no contexto escolar tende a ser percepcionada como uma resposta às necessidades formativas da população que deve assentar em padróes que qualidade.

Este "mecanismo" é entendido como sendo um ponto de partida diferenciado, permitindo percursos distintos e ajustados às reais necessidades de qualificação da população adulta.

Os Directores tendem a percepcionar a imagem que os agentes educativos detêm sobre este "mecanismo" como uma imagem de facilitismo, embora construída com base na comunicação social e outros agentes educativos não afectos ao centro novas oportunidades, que é necessário desconstruir. É importante salientar que este "mecanismo", na perspectiva do director, veio fomentar a aprendizagem ao longo da vida.

Tabela 4. Percepção da Articulação do Centro Novas Oportunidades com o Exterior

\begin{tabular}{ll}
\hline \multicolumn{1}{c}{ Categoria } & \multicolumn{1}{c}{ Exemplo de citaçáo } \\
\hline Vantagem & $\begin{array}{l}\text { “...o envolvimento da escola na comunidade e da comunidade na escola, também } \\
\text { me parece mais interessante nesta modalidade...” }\end{array}$ \\
\hline $\begin{array}{l}\text { Envolvimento } \\
\text { comunitário }\end{array}$ & $\begin{array}{l}\text { “..permite outro tipo de trabalho, temos que ir para o terreno, nos temos pro- } \\
\text { tocolos com empresas, já estamos a trabalhar com as juntas de freguesia, com a } \\
\text { autarquias locais...” }\end{array}$ \\
\hline " & $\begin{array}{l}\text { “.este novo modelo obrigou-nos a ter que definir uma estratégia, tivemos que } \\
\text { definir um plano de acçáo...” “...tivemos que definir uma visáo estratégica de } \\
\text { desafio aos níveis de qualificação da população...” }\end{array}$ \\
\hline
\end{tabular}


Quanto à articulação com o exterior (Tabela 4), é percepcionada como uma mais-valia face ao modelo anterior. É implicada na necessidade de uma definição estratégica, promovendo um papel mais interventivo ao nível da dinamização da comunidade.

A relação entre o Centro Novas Oportunidade e a qualidade (Tabela 5) tende a ser descrita como uma responsabilização ao nível das opçôes políticas nacionais, encontrando-se o órgão de gestáo dos estabelecimentos de ensino (Directores) ausentes no envolvimento quanto à sua definição. Contudo é considerada uma responsabilização das equipas que no desempenho das suas funçôes são as responsáveis pela sua operacionalização.

Tabela 5. Percepção da Relação do Centro Novas Oportunidades com a Qualidade

\begin{tabular}{|c|c|c|}
\hline Categoria & Subcategoria & Exemplo de citaçáo \\
\hline \multirow{2}{*}{$\begin{array}{l}\text { Responsabilidade ao } \\
\text { nível da sua definição }\end{array}$} & Administração Central & $\begin{array}{l}\text { "...os responsáveis pela sua definição estratégica bem } \\
\text { como por uma definiçấo politicamente adequada..." }\end{array}$ \\
\hline & $\begin{array}{l}\text { Agência Nacional para a } \\
\text { Qualificação }\end{array}$ & \\
\hline \multirow{2}{*}{$\begin{array}{l}\text { Responsabilidade ao } \\
\text { nível da sua operaciona- } \\
\text { lizaçáo }\end{array}$} & $\begin{array}{l}\text { Responsabilidade das } \\
\text { escolas }\end{array}$ & $\begin{array}{l}\text { "...é responsabilidade de quem está no terreno e não } \\
\text { de quem as define politicamente..." }\end{array}$ \\
\hline & $\begin{array}{l}\text { Responsabilidade das } \\
\text { equipas }\end{array}$ & \\
\hline Metas & & $\begin{array}{l}\text { "...não sei agora de momento dar-lhe essa indicação, } \\
\text { nấo tenho presente esses números..." }\end{array}$ \\
\hline Qualidade & Compromisso & $\begin{array}{l}\text { "...não estamos dispostos a atingir as metas em } \\
\text { prejuízo da qualidade" }\end{array}$ \\
\hline
\end{tabular}

Ao nível da implicação do Centro Novas Oportunidades na definição vs. redefinição de projectos pessoais e profissionais (Tabela 6), o órgáo de gestáo percepciona-se como ausente do processo. No entanto, prevalece a ideia da existência de um impacto positivo ao nível das dimensóes psicológicas como, por exemplo, o aumento da auto-estima.

Ao nível profissional percepcionam uma inexistência de relação directa entre a elevação dos níveis de qualificação e emprego / projectos profissionais.

Após certificação dos adultos, é visão do órgão de gestão a necessidade de criação de mecanismos de acompanhamento pós processo de reconhecimento, validaçáo e certificação de competências.

Tabela 6. Percepção da Relação Centro Novas Oportunidades e Definição vs. Redefinição de Projectos Pessoais e Profissionais

\begin{tabular}{|c|c|}
\hline Categoria & Exemplo de citaçáo \\
\hline $\begin{array}{l}\text { Distância face ao } \\
\text { processo }\end{array}$ & $\begin{array}{l}\text { "...estamos muito afastados do processo }(\ldots) \text { o momento da entrega de diplomas sinto } \\
\text { que é vivido como muito satisfatório }(. . .) \text { verifico um aumento da auto-estima..." }\end{array}$ \\
\hline $\begin{array}{l}\text { Percepção de competên- } \\
\text { cias nos adultos }\end{array}$ & $\begin{array}{l}\text { "...por via da formaçáa as pessoas ficam mais capacitadas (...) fico com o senti- } \\
\text { mento de melhor preparação para oportunidades futuras em termos de emprego" }\end{array}$ \\
\hline $\begin{array}{l}\text { Ausência de estratégias } \\
\text { de controlo }\end{array}$ & $\begin{array}{l}\text { “...o que me chega por parte dos adultos é muito positivo, mas não conseguimos } \\
\text { ainda ter essa percepção (...) temos tido alguns testemunhos mas não temos noção, } \\
\text { sabemos que em termos pessoais essa melhoria acontece..." }\end{array}$ \\
\hline $\begin{array}{l}\text { Inexistência de relação } \\
\text { directa }\end{array}$ & $\begin{array}{l}\text { "...não existe relação de causa efeito entre a obtençáo de um nível de qualificação } \\
\text { superior ao de entrada no CNO e a vida das pessoas" }\end{array}$ \\
\hline
\end{tabular}




\section{Reflexóes e consideraçóes}

A pretensão de perceber se estará a escola preparada para se Reconhecer como agente, deste trabalho ainda não findo, todavia, a integração destas estruturas no contexto escolar, é percepcionada como uma resposta às necessidades formativas da população que deve assentar em padróes de qualidade.

Constitui-se como ponto de partida diferenciado permitindo, percursos distintos e ajustados às reais necessidades de qualificação da população adulta e veio fomentar a aprendizagem ao longo da vida.

Após certificação dos adultos, é visão do órgão de gestão a necessidade de criação de mecanismos de acompanhamento pós processo de reconhecimento, validaçáo e certificaçáo de competências.

No entanto, prevalece a ideia da existência de um impacto positivo ao nível das dimensóes psicológicas como, o aumento da auto-estima, não se percepcionando uma relação directa entre a elevação dos níveis de qualificação e emprego / projectos profissionais.

Das questóes que se colocam, apraz reflectir sobre se estarão as escolas preparadas para receber este tipo de práticas educativas, quando a reflexividade discursiva, se alicerça em padróes de cariz normativo e orientativo.

\section{Referências Bibliográficas}

Alonso, L. et. al. (2002). Referencial de Competências - Chave - Educação e Formação de Adultos. Lisboa: Agência Nacional de Educação e Formação de Adultos. Parlement Européen (2006).

Agência nacional para a Qualificação (2010). Balanço Iniciativa Novas Oportunidades. Lisboa.

Amorim, J. P. (2006). O impacto da educaçâo e formaçâo de adultos no desenvolvimento vocacional e da cidadania - A metamorfose das borboletas. Lisboa: Cadernos de Emprego e Relaçóes de Trabalho N. ${ }^{\circ} 50$.

Araújo, M. C., Coutinho, C. P. (2009). A Iniciativa Novas Oportunidades e o combate à info-exclusão da população adulta. Braga: Universidade do Minho.

Ashton, D. (1999). The Skill Formation Process: a paradigm shift? Journal of Education and Work, 12-3, 347-350.

Azevedo, J. (1998). Voos de borboleta: Escola, trabalho e profissáo. Porto: Asa.

Ball, Stefhen J. (2001). Directrizes Políticas Globais e Relaçôes Políticas Locais em Educação. Currículo sem Fronteiras, v. 1, 2, 99-116.

Brown, P. (1999). Globalisation and the Political Economy of High Skills. Journal of Education and Work, 12 (3), 233-251.

Crespo, C. A., Gonçalves. C. M. \&. Coimbra, J. L. (2001). A formação no mundo global: um dispositivo na promoção de competências transversais. Novos horizontes para a formación profesional: actas do III encontro internacional de Galicia e Norte de Portugal de formácion para o trabalho (2002).

Coimbra, J. L. (2007). Novas oportunidades na educopólis: ensaios para uma política de aprendizagem ao longo da vida. In Políticas de Educação-formação: estratégias e práticas. Lisboa: Concelho Nacional de Educação

Coimbra, J. L. (2000). Formação: Construção de Competências Pessoais e Profissionais para o Trabalho. Actas do II Encontro Internacional de Galicia e Norte de Portugal de formação para o trabalho, 47-56.

Coimbra, J. L., Parada, F. \& Imaginário, L. (2001). Formação ao longo da Vida e Gestão da Carreira. DirecçãoGeral do Emprego e Formação Profissional, Ministério do Trabalho e da Solidariedade.

Comissão das Comunidades Europeias (2000). Memorando sobre Aprendizagem ao Longo da Vida.

Comissão das Comunidades Europeias (2001). Tornar o espaço europeu de aprendizagem ao longo da vida uma realidade.

Comissão das Comunidades Europeias (2006). Educação de adultos: nunca é tarde para aprender.

Comunidades Europeias (2008). Quadro Europeu de Qualificaçôes para a aprendizagem ao longo da vida (QEQ).

Conselho da Uniāo Europeia (2007). Novas competências para novos empregos. 
Crespo C. A., Gonçalves, C. M., Coimbra J. L. (2001). A formação no mundo global: um dispositivo na promoção de competências transversais, Direcção-Geral de Estudos, Estatística e Planeamento \& Ministério do Trabalho e da Solidariedade Social (2005). Estudo de avaliação das políticas de aprendizagem ao longo da vida. Lisboa: Colecção Cognitum.

Imaginário, L. (1999). A Valorização da Formação Profissional através da Alternância. Lisboa: Ministério do Trabalho e da Solidariedade, Direcção Geral do Emprego e Formação e Comissão Interministerial para o Emprego.

Lima, L. (2002). Formaçâo e aprendizagem ao longo da vida: entre a mão direita e a mão esquerda de Miró. In Quintilha Alexandre et al., Cruzamento de saberes, aprendizagens sustentáveis. Lisboa: Fundação Calouste Gulbenkian.

Pires, A. (2007). Reconhecimento e Validação das Experiências. Uma problemática educativa. Revista de Ciências da Educação, 2, 5-19.

Sitoe, R. M. (2006). Aprendizagem ao Longo da Vida: Um conceito utópico? Comportamento Organizacional e Gestấo. Lisboa: Instituto Superior de Psicologia Aplicada Vol. 12, 2, 283-290. 
Série Documentos

Imprensa da Universidade de Coimbra

Coimbra University Press

2011

- U

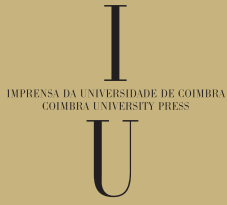

